\title{
EUROPEAN ETFE-DESIGN - NEW FINDINGS AND CONCEPTS
}

\author{
N. STRANGHÖNER ${ }^{*}$, F. SURHOLT ${ }^{*}$, D. RUNGE ${ }^{*}$ AND J. UHLEMANN ${ }^{*}$ \\ ${ }^{*}$ University of Duisburg-Essen, Institute for Metal and Lightweight Structures, Universitaetsstr. 15, \\ 45141 Essen, Germany \\ e-mail: natalie.stranghoener@uni-due.de,felix.surholt@uni-due.de,dominik.runge@uni-due.de, \\ joerg.uhlemann@uni-due.de,web page:www.uni-due.de/iml/
}

Key words: ETFE, design, stress-strain behaviour, hysteresis tests, creep tests

Summary. The plenary lecture on European ETFE-design aims to give an insight into the ongoing development of standardization and research activities for foil structures. With the publication of the Technical Specification prCEN/TS 19102, the European Committee for Standardization (CEN) will provide for the first time a European standard for the design, analysis and execution of buildings and structural works made from structural membrane material. This includes many kinds of tensioned membrane structures. The term "membranes" includes fabrics as well as foils in general and ETFE foils in particular. In this standard, a new design concept for foil structures is established, harmonized among experts across Europe. The safe and economic design of foil structures presupposes a comprehensive understanding of the material and seam behaviour. For this purpose, an overview is given on different research projects which examine the short- and long-term behaviour of ETFE-foils and their weldments. Subject of these projects are for example the tensile, creep and relaxation behaviour of the base material under uniaxial and biaxial stress ratios as well as the tensile behaviour of the weld seams. Another main emphasis of the research of ETFE weld seams is the optimization of the welding and testing procedure. The achieved knowledge will strengthen and enrich the achieved state of the Technical Specification prCEN/TS 19102 in the domain of ETFE-foil structures design.

\section{INTRODUCTION}

In the frame of the currently ongoing standardization work, a novel Technical Specification (TS) prCEN/TS 19102 "Design of tensioned membrane structures"1 is under development. This Technical Specification is the result of a close cooperation between experts from publicly funded research institutes, building authorities, testing institutes, textile membrane and foil manufacturers, membrane producers and engineering offices. With the release of the final CEN/TS 19102, the European Committee for Standardization (CEN) will provide the first harmonized European standard covering the structural design of tensioned membranes structures, including technical textiles and foils. The standard aims to give guidelines for all technical textiles and foils, but focusing on PTFE coated glass fibre fabrics, PVC coated PET fabrics as wells as ETFE-foils. prCEN/TS 19102 provides guidelines for the basis of design, materials, durability, connections, and execution of membrane structures. In the frame of this paper, an overview of the current, final draft of prCEN/TS 19102 is given, focusing on the design of ETFE foils regarding the Ultimate and Serviceability Limit States (ULS and SLS), including background information based on different German research 
projects covering the base material and welded material of ETFE foils.

Within these research projects, new design criteria for ETFE-foils have been and will be derived with the aim of providing safe and economic design approaches.

\section{BASIS OF DESIGN AND LIMIT STATES}

The design process of tensioned membranes structures, independent of the used membrane material, can be divided into four general steps. Starting with the form findings analysis, depending on the proposed geometrical boundary conditions, e. g. columns, prestress level and stress ratio between the material directions, the structural analysis can be performed. The basic principles of the structural design according to prCEN/TS 19102 follow the given principles in EN $1990^{2}$ differentiating between ULS and SLS and implementing partial safety factors $\gamma_{F}$ for the action effects due to external loads and $\gamma_{M}$ for the resistance properties of the used materials. Herein, the given design approaches in prCEN/TS 19102 are applicable for mechanically and pneumatically prestressed membrane structures as well as for double curved and flat construction elements. Due to the interaction between the structure's geometry and its design, the structural analysis is often an iterative process, e. g. the combination and interaction between the structural integrity, chosen initial prestress level and form found geometry. ${ }^{1}$

With the proven stability verifications of the structure, two basic design steps can be derived. From the form found geometry the cutting pattern generation is conducted, dividing
the spatial geometry into flat cutting patterns, while considering the compensation to achieven
the required prestress level. Lastly, the construction is carried out, considering fabrication,
transportation and erection. The individual steps and their descriptions in prCEN/TS 19102
are listed in Table 1.

Table 1: Design steps for the design of membrane structures ${ }^{1}$

Register for free at https//wwwscipedia.com to download the version without the watermark

\begin{tabular}{|l|l|l|l|}
\hline $\begin{array}{l}\text { - Form depending on } \\
\text { the geometry of the } \\
\text { boundaries and the } \\
\text { prestress }\end{array}$ & $\begin{array}{l}\text { - Load assumptions for } \\
\text { spatial surface }\end{array}$ & $\begin{array}{l}\text { - Division into singie } \\
\text { cutting patterns }\end{array}$ & $\begin{array}{l}\text { - Planning of the } \\
\text { erection and } \\
\text { prestressing } \\
\text { procedure }\end{array}$ \\
& $\begin{array}{l}\text { - Assumption of } \\
\text { appropriate material } \\
\text { stiffness properties } \\
\text { plane unstressed } \\
\text { patterns }\end{array}$ & & \\
& - Structural analysis & & \\
\hline
\end{tabular}

Focusing on the structural analysis and following the principles of EN 1990, EN $1991^{3}$ and $\mathrm{prCEN} / \mathrm{TS} 19102$, the design values $\mathrm{R}_{d}$ and $\mathrm{R}$ for foils are calculated. Herein, $\mathrm{R}_{d}$ represents the design value in ULS design and $\mathrm{R}$ is the design value in SLS design. For foils, the design concept of Minte ${ }^{4}$ is taken up and modified to equation (1):

$$
R_{d}(\text { or } R)=\frac{1}{\gamma_{M}} R_{k}\left(k_{\text {age }} ; k_{\text {biax }} ; k_{\text {dur }, *} ; k_{\text {temp }, *} ; k_{\text {single }} ; k_{x}\right)
$$


Herein, $R_{k}$ describes the characteristic resistance value of the material as the $5 \%$-fractile value derived from uniaxial tensile tests according to special provisions in Annex $\mathrm{E}$ of $\mathrm{prCEN} / \mathrm{TS}$ 19102. Alternatively, $\mathrm{R}_{\mathrm{k}}$ can be taken as the nominal characteristic value defined in prCEN/TS 19102 as the mandatory requirement. Furthermore, the design considers modification factors $\mathrm{k}$ have to be considered with which the resistance is reduced taking into account various effects. For example, strength reducing effects derive from increased temperatures $\left(\mathrm{k}_{\mathrm{temp}, *}\right)$ or effects due to long-term loads $\left(\mathrm{k}_{\mathrm{dur}, *}\right)$, respectively. Furthermore, special provisions apply for single layer structures, which are mechanically prestressed and therefore more sensitive to non-permitted plastic deformations and a higher range of tolerances. To take these effects into account, a modification factor $\mathrm{k}_{\text {single }}$ is considered in the SLS design.

\subsection{Ultimate Limit State (ULS)}

In the ULS design of technical foils used in architectural intend, the action effects $E_{\mathrm{d}}=\mathrm{f}_{\mathrm{Ed}}$, due to external loads including the partial safety factor $\gamma_{\mathrm{F}}$ have to be less than the design resistance value of the used material $R_{d}=f_{R d, \text { mod, }}$ cf. equation (2). This criterion applies to every location of the foil:

\section{$f_{E d} \leq f_{R d, m o d}$}

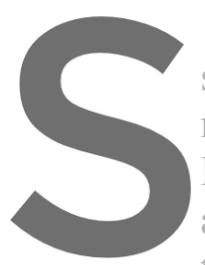

$\mathrm{f}_{\mathrm{R} d, \mathrm{mod}}$ is related to strength of the base 1 modification factors Different default design altitude", the effects of the load duration (Kdur,M) and of tower temperature
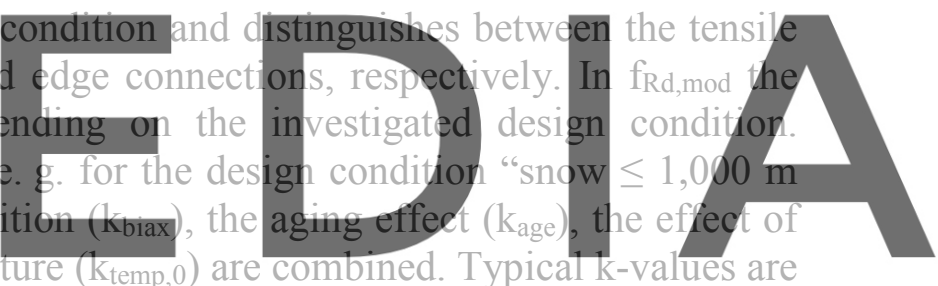
given in Annex C of prCEN/T.S 19102

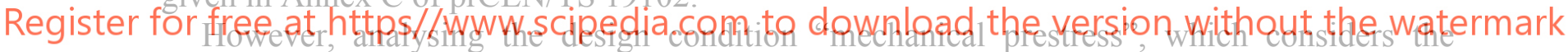
decisive influences for a single layer foil, the biaxial effect ( $\left.\mathrm{k}_{\text {biax }}\right)$, the aging effect $\left(\mathrm{k}_{\mathrm{age}}\right)$ and the effect of increased temperatures $\left(\mathrm{K}_{\text {temp,50 }}\right)$ are taken into account

Due to the requirement that for every location in the foil structure the weakest point has to be proven, either the tensile strength of the base material or the tensile strength of weldments is crucial, see equation (3.2)

$$
\begin{gathered}
f_{R d, \text { mod }}=\frac{f_{R d}}{k_{\text {age }} \cdot k_{\text {biax }} \cdot k_{\text {dur }, *} \cdot k_{\text {temp },{ }^{*}}} \\
f_{R d}=\min \left\{\begin{array}{l}
f_{1, R d}=f_{u 23} / \gamma_{M 0} \\
f_{2, R d}=f_{u w 23} / \gamma_{M 1}
\end{array}\right.
\end{gathered}
$$

The requirements stated in prCEN/TS 19102 for the base material of ETFE foils is $\mathrm{f}_{\mathrm{u} 23}=40 \mathrm{MPa}$ and for welded ETFE foils $\mathrm{f}_{\mathrm{uw} 23}=30 \mathrm{MPa}$. These values can be used as the nominal characteristic values in the design, which the used materials must fulfil. Alternatively, ultimate tensile strength vales can be derived from uniaxial tensile tests according to EN ISO 523-1 ${ }^{5}$ and $-3^{6}$ with special provisions according to Annex $\mathrm{E}$ of 
$\mathrm{prCEN} / \mathrm{TS}$ 19102. Here, short term tensile tests of test series with at least five specimens at $\mathrm{T}=23{ }^{\circ} \mathrm{C}$ are required. The characteristic values shall be taken as the $5 \%$-fractile with the requirement that the coefficient of variation does not exceed $5 \%$ for base material tests and $8 \%$ for tests on welded seams.

Different partial safety factors $\gamma_{\mathrm{M} 0}$ and $\gamma_{\mathrm{M} 1}$ are applied to the different characteristic values for the base material, and welded connections, respectively. For ETFE base material, the recommended partial safety factor is $\gamma_{\mathrm{M} 0}=1.10$, meaning, under the usage of the nominal characteristic value $f_{\mathrm{u} 23}=40 \mathrm{MPa}$, the design value is $f_{\mathrm{Rd}}=\mathrm{f}_{1, \mathrm{Rd}}=\mathrm{f}_{\mathrm{u} 23} / \gamma_{\mathrm{M} 0}=40 \mathrm{MPa} / 1.10=$ $36.36 \mathrm{MPa}$, independent of the design condition considering $\mathrm{k}$ factors. Due to the fact that $f_{u w 23}$ (nominal characteristic value for the weld) is already lower than $f_{1, R d}, f_{2, R d}$ is decisive, which reflects that weldments are the weakest part of foil structures. Failure under tension will always occur at the edge of weld seams due to the geometrical and mechanical nonlinearity in the foil if no other damage occurs in the base material.

The partial safety factors applied to weldments depend on the quality control and quality level of each manufacturer. In the current draft, prCEN/TS 19102 distinguishes between three different inspection levels, QL1, QL2 and QL3. The higher the quality control of the manufacturer in combination with external quality control, the lower is the partial safety factor for welded ETFE foils with $\gamma_{\mathrm{M} 1}=1.45$ for QL1 to $\gamma_{\mathrm{M} 1}=1.15$ for QL3. In order to be qualified for higher quality levels, each individual manufacturer as well as each individual manufacturers' production facitity has to be controiled. For example, a manufacturer ${ }^{2}$ production facility only qualifies for QLB if it has an internal an external, independe Additionally, a certific structures" of prCEN/T the continuous quality eontrol.
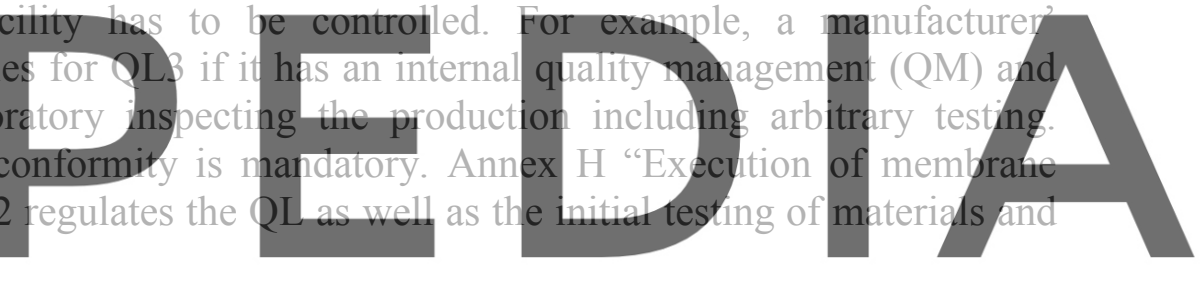

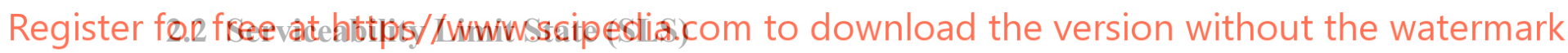

After the ULS criteria are proven, SLS criteria must be fulfilled as well. In SLS design, partial safety factors are applied to the action effects and characteristic resistance values of the material, typically $\gamma_{\mathrm{F}}=\gamma_{\mathrm{M}}=1.0$, which however can be specified in the national annexes. Deflections of the membranes, distances to other parts of the structure, snow and/or water ponding, wrinkling and maintenance of prestress have to be verified. Special provisions for foils apply which are further stress and strain limitations. Due to the highly ductile strain behaviour of ETFE foils, apparent stresses are limited to stresses prior the yield point. As soon as stresses higher than the yield point are present, the strain control of the foil and thus control of deflections and control over the distance to other parts is not ensured anymore. Therefore, in SLS design a new stress resistance value is presented, cf. equation (4):

$$
f_{R} \leq \frac{f_{\text {str23 }}}{\gamma_{M, s e r}}=\frac{f_{s t r 23}}{1.0}
$$

$\mathrm{f}_{\text {str23 }}$ represents a stress limit derived from biaxial tensile tests according to Annex E "Test procedures to determine foil properties" of prCEN/TS 19102. Depending on the structure and the permitted plastic deformations, $f_{s t r 23}$ can be set to the foil's elastic limit derived from 
uniaxial tensile tests at $\mathrm{T}=23{ }^{\circ} \mathrm{C}$. Here, the $5 \%$-fractile is mandatory as well. A recommended elastic limit for ETFE foils is $\mathrm{f}_{\mathrm{e} 23}=15 \mathrm{MPa}$, which depends on the test speed and foil material, cf. chapter 4 .

Following the principles of ULS design, the characteristic stress limit $f_{R}$ is modified using $\mathrm{k}$ factors listed in Annex C. The same design situations apply in SLS as in ULS design. A differentiation is made between cushion structures, prestressed by inner pressure, and single layer structures, which are mechanically prestressed. Due to the variable inner pressure of cushion structures, the plastic strain can be compensated. Herewith, higher stress limits can be applied for cushions in SLS design. Contrary to cushion structures, single layer structures are not allowed to exhibit plastic strains. Any existing plastic strain due to acting loads lowers the initial prestress, which is crucial for the integrity of the foil structure. Without prestress, wrinkling occurs and e. g. wind loads can lead to fatigue. However, the initial prestress should not be too high due to stress relaxation effects. Therefore, special provisions apply for singlelayer structures.

Additionally, creep and relaxation effects should be considered in the design. In single layer structures, if viscoelastic deformations occur, the initial prestress cannot be maintained.

3 TEST PROCEDURES TO DETERMINE FOIL PROPERTIES ACCORDING TO ANNEX E OF prCEN/TS $19102^{1}$

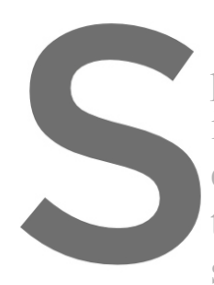

Annex E of prCFi

is that each manufactur

commonly used matarial

tensile and creep tests

structures. Typically occurring stress ratios in
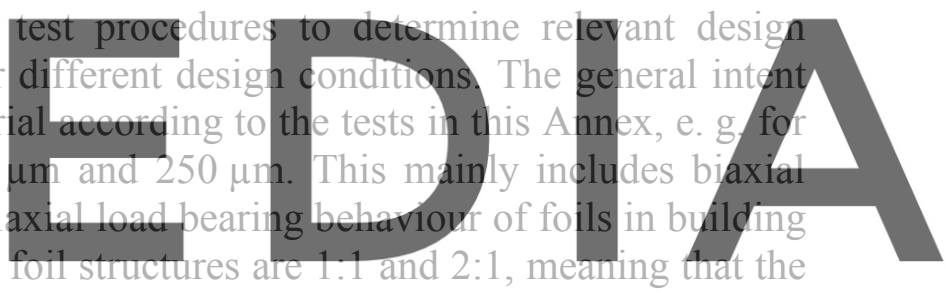

stresses in the two foil directions, extrusion direction (ED) and transversal direction (TD), are

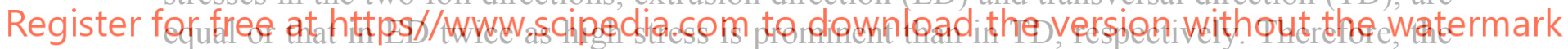

two mentioned stress ratios have to be investigated. If other stress ratios appear in foil

structures, additional tests can be performed.

To record mechanical effects due to long term loads, such as prestress or snow loads, biaxial creep tests are described in Annex E. Hereby, creep tests at three different temperatures $\left(\mathrm{T}_{1}=0{ }^{\circ} \mathrm{C}, \mathrm{T}_{2}=23{ }^{\circ} \mathrm{C}, \mathrm{T}_{3}=50{ }^{\circ} \mathrm{C}\right)$ and with seven load levels, which are defined for ED to $\sigma_{\mathrm{c}, 1}=4 \mathrm{MPa}, \sigma_{\mathrm{c}, 2}=6 \mathrm{MPa}, \sigma_{\mathrm{c}, 3}=8 \mathrm{MPa}, \sigma_{\mathrm{c}, 4}=10 \mathrm{MPa}, \sigma_{\mathrm{c}, 5}=15 \mathrm{MPa}$, $\sigma_{\mathrm{c}, 6}=18 \mathrm{MPa}, \sigma_{\mathrm{c}, 7}=24 \mathrm{MPa}$, are suggested. After the creep test is carried out, reverse creep should be measured as well. Annex E recommends a creep time of 1,000 $\mathrm{h}$ and a reverse creep time of $72 \mathrm{~h}$. Figure 1 illustrates the recommended load protocol for the creep and reverse creep tests. With the determined creep and reverse creep behaviour, stress limits can be defined for SLS design. Plastic strains due to long term loads can decrease the required prestress and can lead to increased loads in the event of snow or water ponding.

Furthermore, biaxial short-term hysteresis tests are described in Annex E. The given load protocol simulates a windstorm building up acting on cushion structures. The intention of these tests is to derive the mechanical foil behaviour of a cushion under cyclic loading at different temperatures and load levels. Here, nine different load levels are suggested, which 
gradually increase in one biaxial tensile test (stress ratio 1:1 or 2:1 and test temperatures $\mathrm{T}_{1}=0{ }^{\circ} \mathrm{C}, \mathrm{T}_{2}=23{ }^{\circ} \mathrm{C}$ or $\mathrm{T}_{3}=50{ }^{\circ} \mathrm{C}$ ). Starting at the common prestress level of $\sigma_{\mathrm{P}}=4 \mathrm{MPa}$, which is held for $t_{\text {ini }}=10 \mathrm{~min}$., the first load level is applied with $\sigma_{1}=8 \mathrm{MPa}$. To simulate wind gusts, 50 load cycles in each load level are performed between $100 \%$ and $60 \%$ of the investigated load level.

To simulate the wind speed, each load level shall be met in $5 \mathrm{sec}$. After the first 50 cycles, the initial prestress level is held constant again for at least $\mathrm{t}_{\text {relax }}=10 \mathrm{~min}$. The maximum strain $\varepsilon_{\text {sat }}$ after 50 load cycles as well as the strain after the relaxation time $\varepsilon_{\text {res }}$ are measured. This segment is repeated for the other load levels ending at $\sigma_{9}=26 \mathrm{MPa}$. Figure 2 illustrates the load protocol for the first three load levels. Figure 3 shows a stylized stress strain path of the first load level in one material direction as well as strain values, which can be measured or calculated from the test. From these biaxial hysteresis tests, stiffness parameters and strain parameters can be

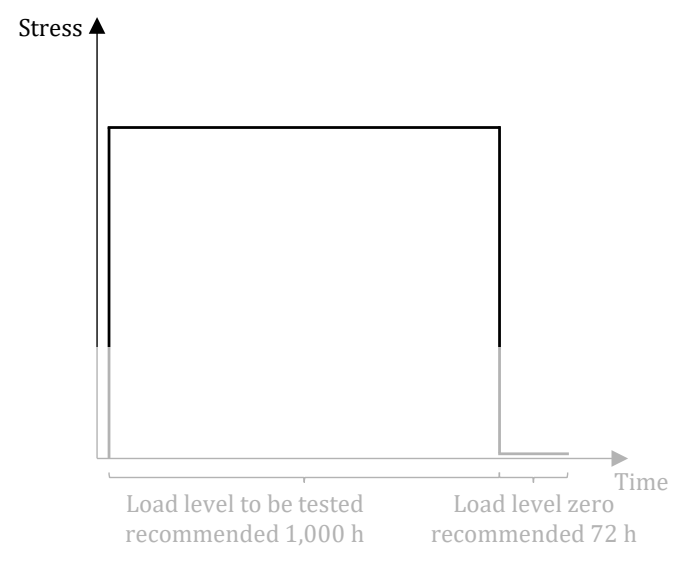

Figure 1: Illustrated load protocol for biaxial creep tests in one material direction

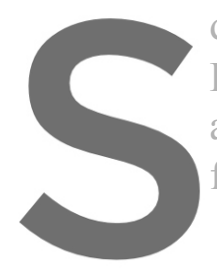
derived, see Figure 3

ETFE foils are homoge are calculated per load for the Hooke's strain
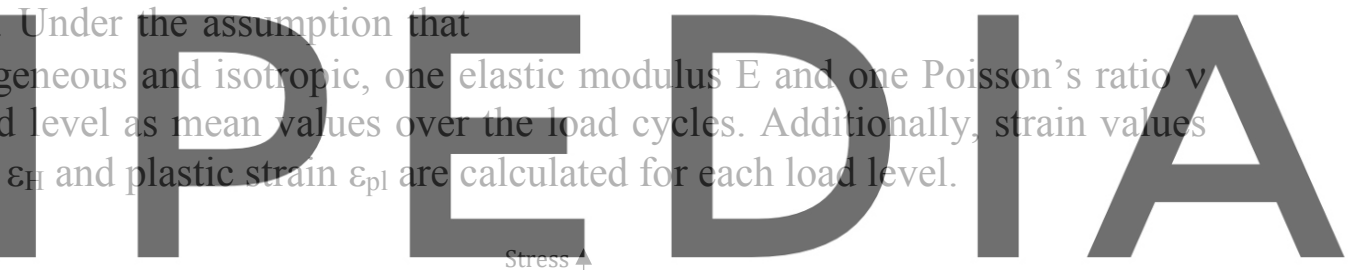
Stress 4

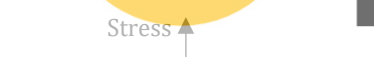

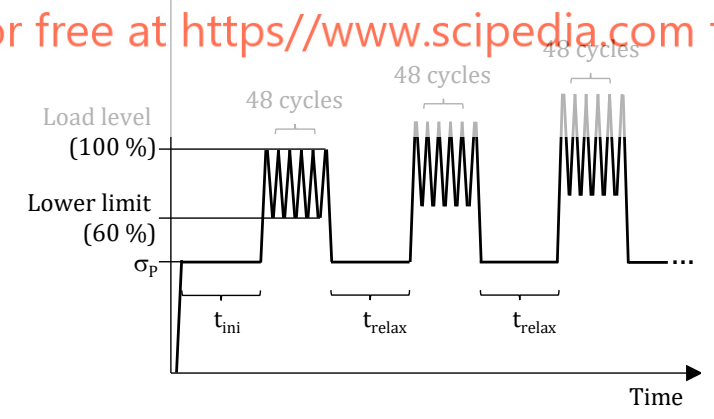

Figure 2: Illustrated load protocol for biaxial hysteresis tests in one material direction

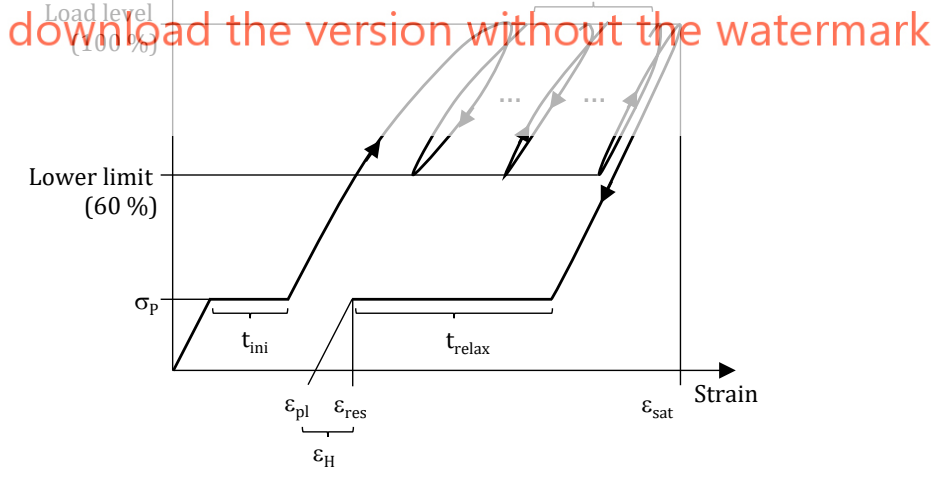

Figure 3: Stress strain paths of the biaxial hysteresis tests, illustrated for the first load level and one material direction

Exemplary, biaxial tensile hysteresis tests at the three mentioned temperatures according to these load protocols were performed for ETFE foils of $250 \mu \mathrm{m}$ thickness from two different foil producers $\mathrm{A}$ and $\mathrm{C}$. The focus was set on the relaxation time $\mathrm{t}_{\text {relax }}=10 \mathrm{~min}$. Six biaxial hysteresis tests were carried out in stress ratio $2: 1$, so for each test temperature and 
manufacturer one test was carried out. Deviating from the protocol in Annex E, the relaxation time between two load levels was set to $60 \mathrm{~min}$ to verify or deny the proposed $10 \mathrm{~min}$.

Out of the biaxial hysteresis tests, the relaxation strain paths were extracted, normalized, and then approximated by an asymptotic function ${ }^{7}$. Figure 4 illustrates the extracted residual strains in ED of one biaxial hysteresis test at $\mathrm{T}=23^{\circ} \mathrm{C}$ for a third material manufacturer $\mathrm{C}$. Starting at a load level of $18 \mathrm{MPa}$, first significant residual strains are evident, $\varepsilon_{\text {res }}(t=60 \mathrm{~min}.) \cong 0.5 \%$. With the next load level, the increase in residual strains after $60 \mathrm{~min}$ relaxation time is over-linear.

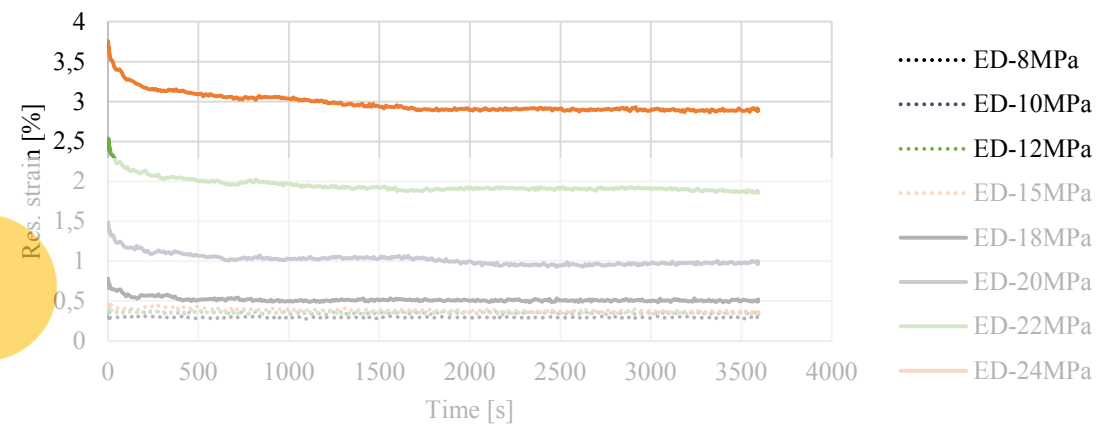

Figure 4: Curves of the inspected reverse creep behaviour over trelax $=60 \mathrm{~min}$. in ED of ETFE foil,
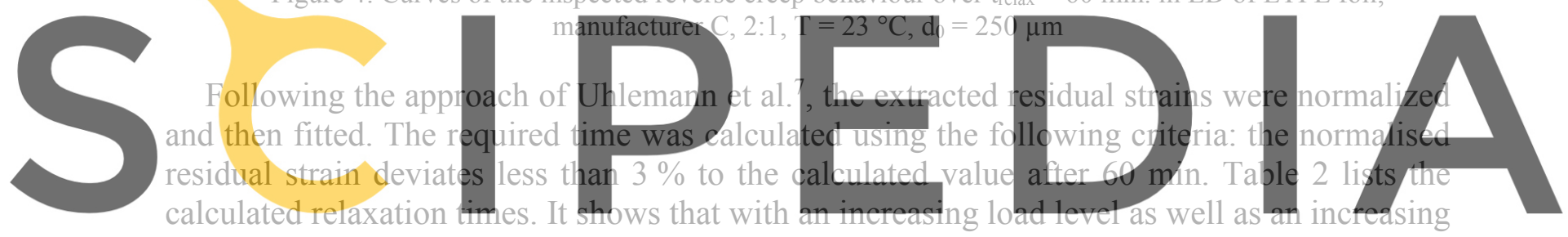

test temperature, the required relaxation time also increases.

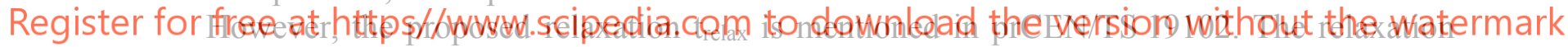

time of $10 \mathrm{~min}$. can be taken as safe sided due to the overestimation of residual strain after biaxial cyclic loading. Nonetheless, for a more specific and economic design of ETFE foils, longer relaxation times are suggested, which can be even greater than the investigated 60 min.

Table 2: Relaxation times $t_{\text {relax }}[\mathrm{min}]$ depending on the test temperature with $3 \%$ deviation to the residual strain after $60 \mathrm{~min}$

\begin{tabular}{|c|c|c|c|c|c|c|c|c|c|c|c|}
\hline \multirow{2}{*}{$\begin{array}{c}\mathrm{T} \\
{\left[{ }^{\circ} \mathrm{C}\right]}\end{array}$} & \multirow{2}{*}{ Manu. } & \multicolumn{10}{|c|}{ Load level [MPa] } \\
\cline { 3 - 14 } & & 8 & 10 & 12 & 15 & 18 & 20 & 22 & 24 & 26 \\
\hline \multirow{2}{*}{0} & $\mathrm{~A}$ & 0.3 & 2.7 & 11.8 & 22.1 & 29.7 & 38.6 & 33.9 & 22.4 & 17.8 \\
\cline { 2 - 15 } & $\mathrm{C}$ & 0.1 & 4.7 & 0.3 & 11.8 & 26.5 & 28.6 & 26.3 & 36.4 & 30.6 \\
\hline \multirow{2}{*}{23} & $\mathrm{~A}$ & 0.2 & 21.0 & 35.9 & 26.7 & 8.7 & - & - & - & - \\
\cline { 2 - 14 } & $\mathrm{C}$ & 0.3 & 2.5 & 2.1 & 15.2 & 19.1 & 25.0 & 17.3 & 17.3 & - \\
\hline \multirow{2}{*}{50} & $\mathrm{~A}$ & 9.0 & 1.2 & 14.3 & 17.8 & 16.7 & - & - & - & - \\
\cline { 2 - 13 } & $\mathrm{C}$ & 8.6 & 1.6 & 13.0 & 19.3 & 16.2 & 15.9 & - & - & - \\
\hline
\end{tabular}

Simultaneously, stiffness parameters were derived following the evaluation procedure in 
Annex E. For each load level, one stiffness parameter E and one Poisson's ratio $v$ were calculated, see Table 3. Poisson's ratios greater than 0.50 are crossed. The evaluation shows that the foils of different material producers exhibit different material properties. According to the scope and field of Annex E, every material producer should characterise its own material for the most common material thicknesses. Additionally, material producers should deliver uniaxial test data, following the test protocol in Annex E.6. Uniaxial tensile tests on ETFE foils should be performed using one strip specimen linearly clapped with a width to length ratio of 1:5 and a test speed of $200 \% / \mathrm{min}$. Herewith, designers can calculate structures with tabulated values, which can be verified using uniaxial test data. If the material properties drastically change, uniaxial tensile tests will show it, so that new biaxial creep and hysteresis tests should be performed.

Table 3: Calculated stiffness parameters, evaluation according to Annex E.5

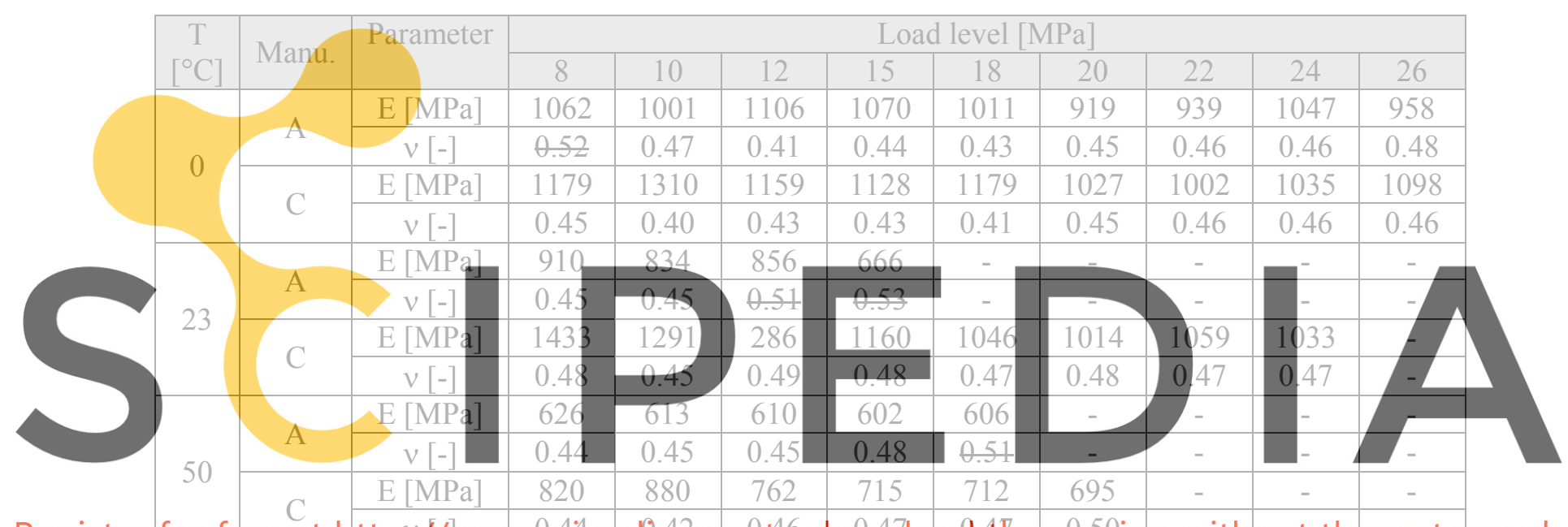

Register for free at https/fwww.stipediat:eomp to downiload. the vepsion without the watermark

\section{RECENT INVESTIGATIONS INTO THE CHARACTERISATION OF THE \\ MECHANICAL PROPERTIES OF ETFE FOILS}

In the German DFG research project "Characterisation of the non-linear viscoelastic material behaviour of ETFE and ECTFE foils for the use in building membrane structures" technical foils are mechanically tested. The central objective of this research project is the fundamental development of comprehensive methods and analytical models for characterising the non-linear viscoelastic material behaviour of ETFE and ECTFE foils for use in membrane structures in the building industry. In a first step, for this purpose, the typical material characteristics of ETFE foils will be determined considering different manufacturers. Since the load-bearing behaviour of the foils is essentially biaxial, the methods and analytical models shall be adapted not only to the uniaxial, but also in particular to the biaxial loadbearing behaviour. For this purpose, both the tensile load-bearing behaviour (uniaxial/biaxial) and the creep and relaxation behaviour (uniaxial/biaxial) are analysed, taking into account the influencing parameters of material thickness, temperature, strain rate, stress ratio in the biaxial stress state, loading history and stress levels in long-term tests. ${ }^{8}$ 
Since the material behaviour under biaxial tension is decisive, it is planned to develop correlations between the uni- and biaxial material behaviour. With the correlations established, including the short-term and long-term behaviour, the biaxial material response could be mapped based on uniaxial test data. For this purpose, in a first step, uniaxial and biaxial short-term and long-term tests are carried out under variation of e.g. five test temperatures and five test speeds.

Additionally, material characterising values depending on the test conditions are determined in these tests. These values will be adopted and considered in the development of the $\mathrm{prCEN} / \mathrm{TS} 19102$ or a future Eurocode for membrane structures. Uniaxial tensile tests on ETFE foils show the material behaviour, which can be influenced by tests speeds and test temperatures. As an example, Figure 5 shows $5 \%$-fractile stress-strain curves from uniaxial tensile tests at a constant test speed $\left(\mathrm{v}_{\mathrm{t}}=100 \mathrm{~mm} / \mathrm{min}\right)$ at three test temperatures $\left(\mathrm{T}_{1}=0{ }^{\circ} \mathrm{C}\right.$, $\mathrm{T}_{2}=23^{\circ} \mathrm{C}, \mathrm{T}_{3}=50^{\circ} \mathrm{C}$ ) in extrusion direction (ED). It shows the material's behaviour of ETFE foils with a nominal thickness of $250 \mu \mathrm{m}$ from three different manufacturers. In Figure 5 a., the complete tensile behaviour is shown, while in Figure 5 b. only the behaviour up to $20 \%$ strain is illustrated. The Figures present the temperature's significant influence on the material's strength independent of the manufacturer. However, the ETFE foil produced by manufacturer A exhibits lower strengths for each test temperature than those foils produced by manufacturers B and C.
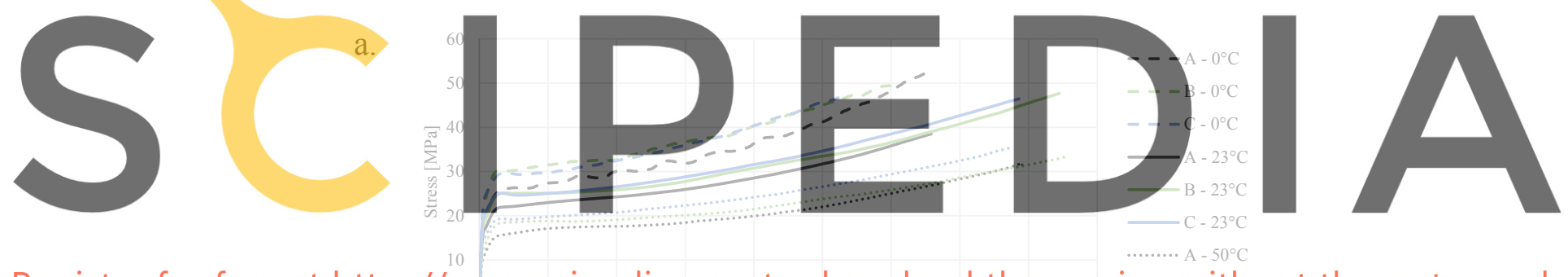

Register for free at https//www.scipedia.com to download the version without the watermark

b.

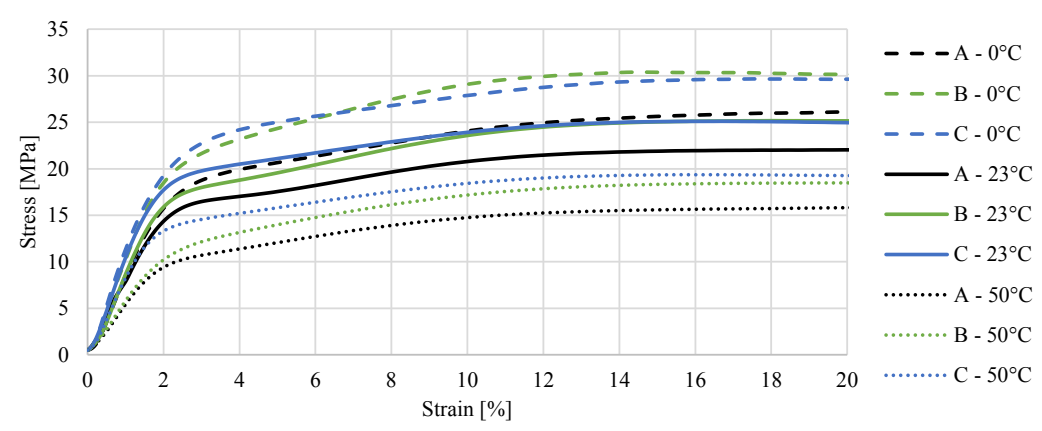

Figure 5: Uniaxial tensile tests of ETFE foil $(250 \mu \mathrm{m})$ at three different test temperatures $\left(\mathrm{T}_{1}=50{ }^{\circ} \mathrm{C}, \mathrm{T}_{2}=23{ }^{\circ} \mathrm{C}, \mathrm{T}_{3}=0{ }^{\circ} \mathrm{C}\right)$ and $\mathrm{v}_{\mathrm{t}}=100 \mathrm{~mm} / \mathrm{min}$ in $\mathrm{ED}$; material producers A, B and C. a. complete paths; b. detailed view up to $20 \%$ strain 
Based on these uniaxial tensile tests, the elastic limits can be extracted. Following Wu et al. ${ }^{9}$, prCEN/TS 19102 gives the user a simplified determination method to derive the elastic limit of an ETFE foil. The method is described in Figure 6. The elastic limit is simplified taken as the first inflexion point in a uniaxially determined stress-strain path. The Figure illustrates a typical stress-strain behaviour of ETFE foil in a uniaxial tensile test. In order to derive the elastic limit, two secants are drawn. The first secant starts from origin up to $1 \%$ strain; the second secant is drawn over $5 \%$ and $8 \%$ strain. The intersection point of these two secants determines the stress level off the elastic limit. Using this method, the $5 \%$-fractile elastic limits for each illustrated stress-strain path in Figure 5 and thus $\mathrm{k}_{\text {temp,* }}$ can be derived

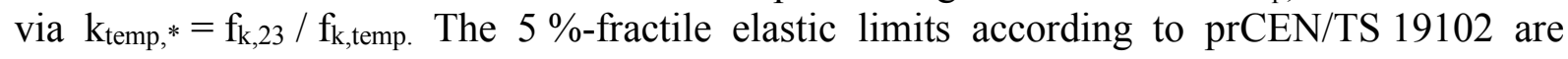
listed in Table 4. Additionally, the elastic modulus E [MPa] are calculated as secant modulus over $0 \%$ strain to $1 \%$ strain $\left(\mathrm{E}_{0 \%-1 \%}\right)$. The defined elastic limit $\mathrm{f}_{\mathrm{el} 23}$ given in prCEN/TS 19102 of $15 \mathrm{MPa}$ is applicable, see Table 4. However, the given value for ktemp,* still has to be revised in prCEN/TS 19102. Currently, in SLS design, ktemp,0 equals 0.8 and ktemp,50 ranges from 1.2 to 1.4. According to the results given in Table 4, $\mathrm{k}_{\text {temp,50 }}$ is proposed to 1.4 to 1.5 instead of 1.2 to 1.4 .
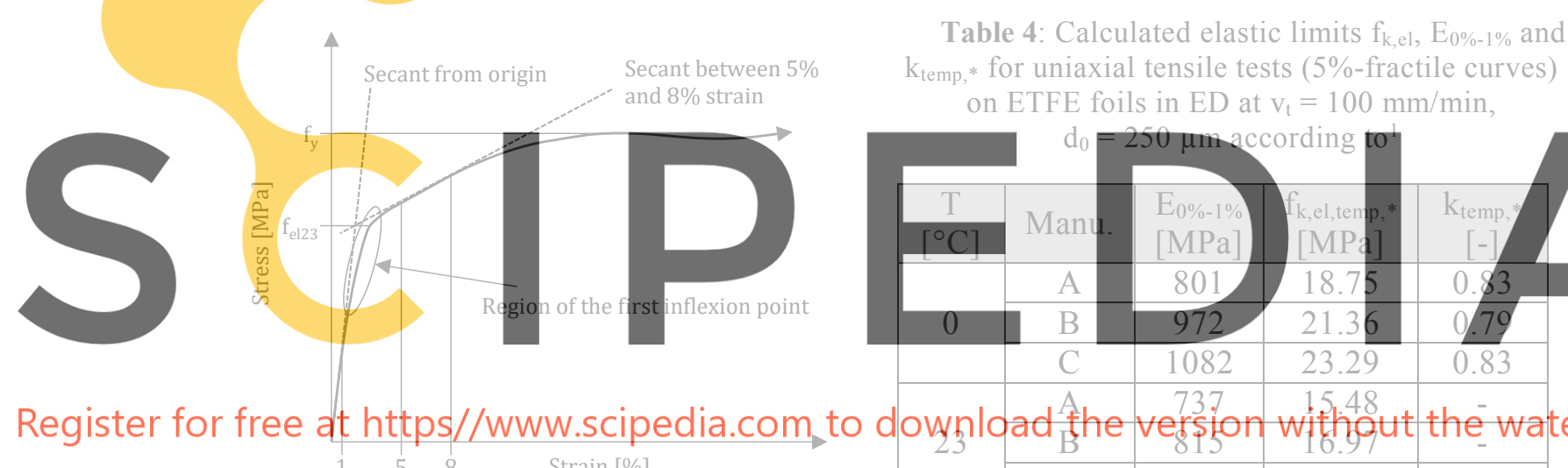

Register for free at https//www.scipedia.com to

Figure 6: Simplified method to determine the elastic limit in a uniaxial stress-strain path
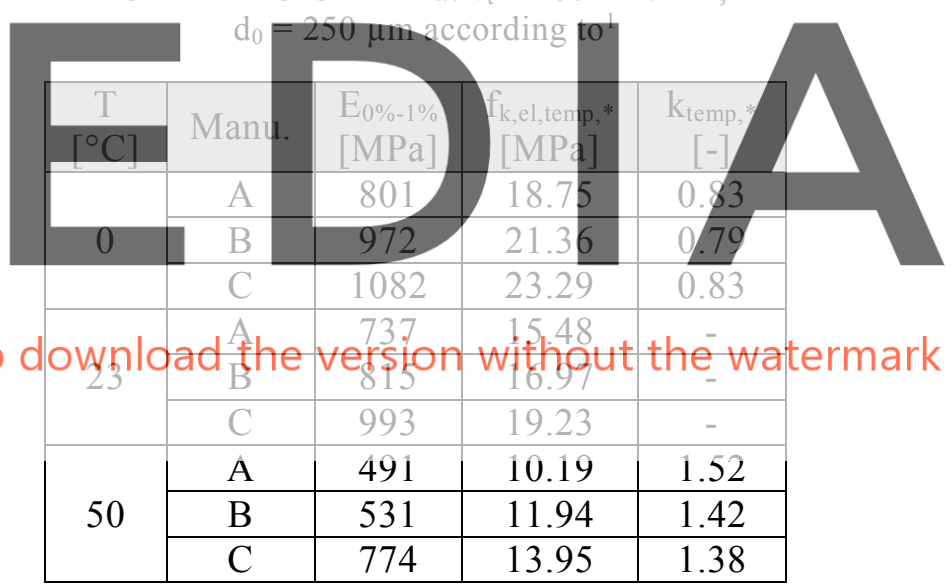

For describing the uniaxial material behaviour, a modified Ramberg-Osgood material model is proposed which is based on the modified Ramberg-Osgood ${ }^{10,11}$ model for stainless steel. This material model allows the determination of the material characteristics and herewith more suitable strain values. The modified material model is given in equation (6):

$$
\begin{array}{cc}
\varepsilon=\frac{\sigma}{E_{1}}+K\left(\frac{\sigma}{f_{1}}\right)^{n} & \text { for } \sigma \leq f_{1} \\
\varepsilon=K+\frac{f_{1}}{E_{1}}+\frac{\sigma-f_{1}}{E_{2}}+\varepsilon_{y}\left(\frac{\sigma-f_{1}}{f_{y}-f_{1}}\right)^{m} & \text { for } f_{l}<\sigma \leq f_{y}
\end{array}
$$

with the material parameters $K, n, m$ and the strength and stiffness parameters $f_{1}, f_{y}, E_{1}$ and 
$\mathrm{E}_{2}$. Herein, $\mathrm{f}_{1}$ is a model parameter which represents the stress level in a stress-strain path where the second linear part starts, for ETFE foils typically occurring after the first inflexion point. $f_{y}$ is the yield point, commonly referred to as the second yield point, $E_{1}$ is the elastic modulus calculated as a regression line over $0.3 \%$ and $0.5 \%$ strain and $\mathrm{E}_{2}$ is the stiffness after the first inflexion point calculated as a regression line over $5.0 \%$ and $5.2 \%$ strain. Using this method, the following model parameters were determined for the $5 \%$-fractile curves as shown in Figure 5. The error terms $\mathrm{S}_{\mathrm{e}, 1 / 2 \text {,mean }}$ give the mean strain error between the model and the test curves, see Table 5. In a first step the input parameter for the Ramberg-Osgood model were derived on the basis of the experimental results. In future work, generalised input parameters have to be developed which allow the theoretical determination of the stress-strain behaviour of ETFE foils on the basis nominal input values.

The calculated curves as well as the experimental 5\%-fractile curves are illustrated in Figure 7 for the material of manufacturer A. Note, that the material model only applies up to the individual, calculated yield points $\mathrm{f}_{\mathrm{y}}$ and shows at this step a good fit.

Table 5: Calculated model parameters for uniaxial tensile tests (5\%-fractile curves) on ETFE foils in ED at $\mathrm{v}_{\mathrm{t}}=100 \mathrm{~mm} / \mathrm{min}, \mathrm{d}_{0}=250 \mu \mathrm{m}$, material manufacturer $\mathrm{A}$

\begin{tabular}{|c|c|c|c|c|c|c|c|c|c|c|}
\hline $\begin{array}{c}\mathrm{T} \\
{\left[{ }^{\circ} \mathrm{C}\right] .}\end{array}$ & $\begin{array}{c}\mathrm{f}_{1} \\
{[\mathrm{MPa}]}\end{array}$ & $\begin{array}{c}\mathrm{f}_{\mathrm{y}} \\
{[\mathrm{MPa}]}\end{array}$ & $\begin{array}{c}\varepsilon_{\mathrm{y}} \\
{[\%]}\end{array}$ & $\begin{array}{c}\mathrm{E}_{1} \\
{[\mathrm{MPa}]}\end{array}$ & $\begin{array}{c}\mathrm{E}_{2} \\
{[\mathrm{MPa}]}\end{array}$ & $\begin{array}{c}\mathrm{K} \\
{[-]}\end{array}$ & $\begin{array}{c}\mathrm{n} \\
{[-]}\end{array}$ & $\begin{array}{c}\mathrm{m} \\
{[-]}\end{array}$ & $\begin{array}{c}\mathrm{S}_{\mathrm{e}, 1, \text { mean }}[-] \\
{[-]}\end{array}$ & $\begin{array}{c}\mathrm{S}_{\mathrm{e}, 2, \text { mean }} \\
{[-]}\end{array}$ \\
\hline 0 & 19.92 & 25.98 & 0.052 & 923 & 69 & 0.017 & 8.68 & 9.56 & 0.008 & 0.002 \\
\hline 23 & 17.19 & 21.93 & 0.036 & 892 & 62 & 0.023 & 13.78 & 14.57 & 0.012 & 0.008 \\
\hline 50 & 10.39 & 15.72 & 0.067 & 485 & 69 & 0.005 & 20.94 & 11.78 & 0.010 & 0.012 \\
\hline
\end{tabular}

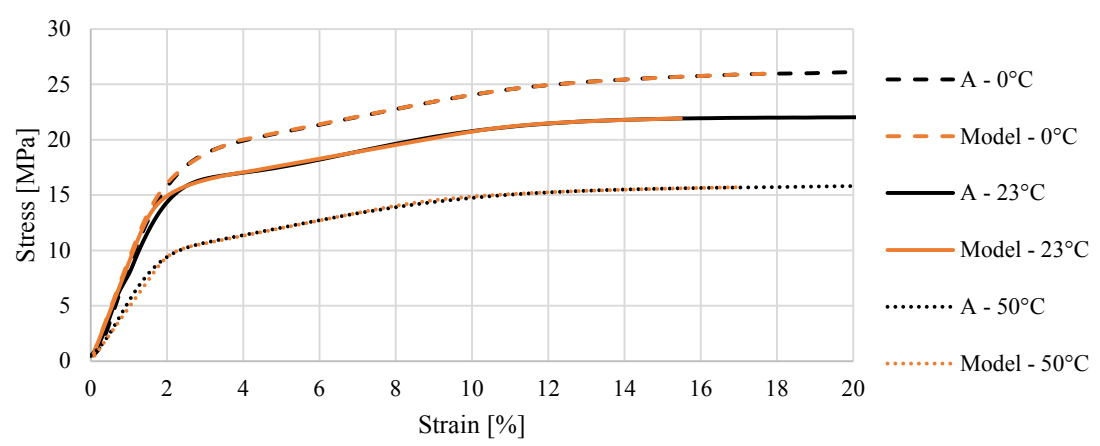

Figure 7: Comparison of uniaxial $5 \%$ fractile stress-strain curves and modelled curves of man. A.

\section{INVESTIGATIONS INTO WELDED ETFE CONNECTIONS}

The German WIPANO research project "Welded connections for ETFE foils in construction: Standardization of execution, testing and design" has the objective to standardise processes and design methods for welding and welded ETFE foil structures. The project is a joint project of six project partners whereby the Institute for Metal and Lightweight Structures of the University of Duisburg-Essen with the associated Essener Labor für Leichte Flächentragwerke (ELLF) acts as the coordinator. The further project partners are DEKRA`s Testing Laboratory for Technical Textiles and Foils, Stuttgart, Vector Foiltec GmbH, Bremen, Taiyo Europe $\mathrm{GmbH}$, Stuttgart, se cover GmbH, Obing, and Form TL Ingenieure für Tragwerke und Leichtbau GmbH, Radolfzell am Bodensee, all Germany. ${ }^{12}$ 
The objective of the WIPANO research project is to develop a harmonized procedure for testing of ETFE weld seams by means of experimental and numerical investigations of the base and welded material. Herein, the specimen geometry, the manufacturing method, the testing speed and the clamping technique as well as the respective tolerances will be taken into account. ${ }^{12}$ Furthermore, a welding procedure test and a concept for the qualification of the welding staff shall be developed and verified. ${ }^{12}$ As another main goal of the research project, a fractile value for the minimum strength of ETFE field welds shall be determined considering different material manufactures, foil thicknesses and temperatures.

The new findings regarding the optimized testing procedure, the concepts for the execution of ETFE field welds as well as the determined and verified minimum strength values shall be directly implemented in a future version of the prCEN/TS 19102. ${ }^{12}$

In the meantime, in a first step, the objective of this project is to draft a standardization document, e.g. a DIN SPEC, which standardizes the execution and testing of ETFE foil welds. The long-term objective is to introduce this DIN SPEC into the standardization work at European level and, on this basis, to develop a harmonized European standard for the execution and testing of welded foil seams. Furthermore, the design of weld seams is checked and further developed. ${ }^{12}$

\section{CONCLUSIONS}

With the development of the prCEN/TS 19102, which follows the principles of the Eurocodes, the first European harmonized design guide will be released for membrane structures. This European standard merge the design, analysis, durability, connections, execution, and material characteristics. New design concepts for the ULS and SLS were presented with special provisions for foils in SLS design. The SLS design for ETFE foils proposes new stress limitations in order to guarantee a control over plastic strains. Especially, for single layer structures plastic strains, as they can appear in cushion structures, are not tolerable.

The knowledge obtained in the German research projects for the base material as well as for welded ETFE connections are to be implemented directly at European level into the prCEN/TS 19102 "Design of tensioned membrane structures", which is currently in its final draft, and into the Eurocode for membrane structures, which is subsequently to be developed from it.

\section{ACKNOWLEDGMENTS}

The authors gratefully acknowledge the funding of this research by the Deutsche Forschungsgemeinschaft (DFG) in the framework of the research project „Characterisation of the non-linear viscoelastic material behaviour of ETFE and ECTFE foils for the use in building membrane structures" (GZ: STR 482/6-1) and the producers providing material, AGC Chemicals Europe Ltd., Nowofol ${ }^{\circledR}$ Kunststoffprodukte GmbH \& Co. KG and Textiles Coated International (TCI).

The authors also gratefully acknowledge the funding of this research by the WIPANO initiative of the German Federal Ministry for Economic Affairs and Energy in the framework of the research project „Welded connections for ETFE foils in construction: Standardization 
of execution, testing and design" and the producers providing material, AGC Chemicals Europe Ltd. and Nowofol ${ }^{\circledR}$ Kunststoffprodukte GmbH \& Co. KG.

\section{REFERENCES}

[1] prCEN/TS 19102:2021-04 (E), Design of tensioned membrane structures (Final Draft).

[2] DIN EN 1990:2010-12, Eurocode: Basis of structural design; German version EN 1990:2002 + A1:2005 + A1:2005/AC:2010.

[3] DIN EN 1991 (all parts), Eurocode 1: Actions on structures - Part 1: general actions

[4] Minte, J., Das mechanische Verhalten von Verbindungen beschichteter Chemiefasern, Dissertation, Technische Hochschule Aachen, Aachen, 1981.

[5] DIN EN ISO 527-1:2019-12, Plastics - Determination of tensile properties - Part 1: General principles (ISO 527-1:2019); German version EN ISO 527-1:2019.

[6] DIN EN ISO 527-3:2019-02, Plastics - Determination of tensile properties - Part 3: Test conditions for films and sheets (ISO 527-3:2018); German version EN ISO 527-1:2018.

[7] Uhlemann, J., Surholt, F., Westerhoff, A., Stranghöner, N., Motevalli, M., Balzani, D. Saturation of the stress-strain behaviour of architectural fabrics, Materials and Design (2020) 191:108584. https://doi.org/10.1016/j.matdes.2020.108584

[8] Stranghöner, N., DFG research project STR 482/6-1, Characterisation of the non-linear viscoelastic material behaviour of ETFE and ECTFE foils for the use in building membrane structures, 2019.

[9] Wu, M., Li, Y., Shang, Y., Statistical Characteristics of Ethylene Tetrafluoroethylene Foil's Mechanical Properties and Its Partial Safety Factors, J. Mater. Civ. Eng. (2016) 28(5):04016004.

[10]Ramberg, W., Osgood, W., R., Description of Stress-Strain Curves by Three Parameters, National Bureau of Standards, Technical Note No. 902, Washington 1943.

[11]SCI Steel Knowledge, Design Manual for Strucutral Stainless Steel, SCI Publication P413, $4^{\text {th }}$ Edition, SCI, Silwood Park, Ascot, Berkshire.

[12] Stranghöner, N., WIPANO research project ETFE, Welded connections for ETFE foils in construction: Standardization of execution, testing and dimensioning, 2020. 